\title{
Renal Myxoma in a Feline
}

\author{
Thayná Oliveira da Silva', Fernanda Zuliani' ${ }^{1}$, Noeme Sousa Rocha' \& Carlos Eduardo Fonseca Alves²
}

\begin{abstract}
Background: Renal neoplasms are a rare condition in felines, with metastatic lymphoma presenting the highest incidence rate. Secondary renal neoplasms are more frequent $(88 \%)$ than primary renal tumors, with primary mesenquimal renal neoplasms accounting for $22 \%$ of the cases and the incidence of benign tumors not exceeding $5 \%$. Myxomas are neoplasms in undifferentiated mesenchymal cells with abundant reproduction of the myxoid matrix, with few few case reports about this type of neoplasm in the veterinary literature. This study reports the first case of renal myxoma in a young feline afflicted by granulomatous nephritis and diagnosed with FIP (Feline Infectious Peritonitis).

Case: A 9-month-old, male, mixed breed feline, was admitted into the Veterinary Hospital maintained by the School of Veterinary Medicine and Animal Science, Botucatu, Brazil, presenting symptoms such progressive weight loss and occasional episodes of emesis for one week, progressing to anorexia, hematochezia, vocalization, lack of coordination, spasms, anuria and inability to defecate. A physical examination revealed moderate dehydration, low temperatures $(<$ $\left.33^{\circ} \mathrm{C}\right)$, dyspnea $(36 \mathrm{mpm})$, slight hyperglycemia $(187 \mathrm{mg} / \mathrm{dL})$ and distension of the abdomen and of the urinary bladder. The hematological assay and the serum biochemistry assay revealed neutrophilic leukocytosis, thrombocytopenia, anemia and slight uremia. In view of the severity of the neurologic signs and lack of response to the clinical treatment, the owner opted to euthanize the animal. The necropsy revealed diffused jaundice, with kidney injuries observed through the pale coloration of the tissue and irregular surface with multiple off-white small nodules distributed in a marked and diffuse way. The same injury pattern was observed markedly in the lungs and discretely in the spleen and liver. The material collected was fixed in a $10 \%$ formalin solution, and processed according to the routine technique (Hematoxylin \& Eosin). The remaining samples were submitted to a histochemical analysis with the Alcian Blue and Masson's Trichrome stains, in addition to an immunohistochemical expression test. The histopathological examination with H\&E staining revealed multiple focuses of pyogranulomatous injuries in the kidneys, lungs, spleen, uvea and leptomeninges, corroborating the diagnosis of feline infectious peritonitis (FIP). In addition, there was a neoplastic proliferation of fusiform cells among an abundant myxoid matrix, evident in Alcian Blue staining. Normal renal tissue, such as glomeruli or tubules, were occasionally observed inside the neoplastic proliferation. Masson's Trichrome technique was used to exclude the possibility of a fibroblastic origin. In addition, immunohistochemistry (IHC) was performed to confirm the diagnosis of myxoma using the Vimentin, pan-cytokeratin and p63 antibodies.

Discussion: Kidney tumors are rare in veterinary medicine, but have an incidence rate four to five times greater in cats than in dogs. The veterinary literature describes myxomas located in joints, cardiac valves and ureter, but reports of myxomas afflicting the kidneys are more commons in human medicine. This tumor should be included in the differential diagnosis process for young cats with suspicions of renal neoplasms, however, to differentiate between neoplasms with a myxoid component in benign tumors. This is the first reported case of renal myxoma afflicting a young feline with feline infectious peritonitis (FIP) in the veterinary literature.
\end{abstract}

Keywords: neoplasm, kidney, feline, myxoid matrix, immunohistochemistry. 


\section{INTRODUCTION}

Renal neoplasms are a rare condition in felines, with metastatic lymphoma presenting the highest incidence rate. Secondary renal neoplasms are more frequent $(88 \%)$ than primary renal tumors, with primary mesenquimal renal neoplasms accounting for $22 \%$ of the cases and the incidence of benign tumors not exceeding 5\%. [4].

Myxomas are benign neoplasms of mesenchymal origin in which fusiform cells are found among an abundant myxomatous matrix created by the excessive production of mucopolysaccharides [10]. They are described in humans as occurring mainly in the heart, skin, bones, soft tissues and other parts of the organism $[5,8]$. This type of tumor is seldom described in Veterinary Medicine and has been reported in a few different locations, but there is only one report of a myxoma in the feline genitourinary system, particularly in the ureter [6]. This study aims at reporting the first case of renal myxoma detected accidently in a feline.

\section{CASE}

A 9-month-old male feline of mixed breed was admitted into the Veterinary Hospital maintained by the School of Veterinary Medicine and Animal Science, Botucatu, SP, Brazil, with a history of adoption two months prior, cachexia and death of the other kittens in the litter. The owner reported progressive weight loss, apathy and occasional episodes of emesis for one week, progressing to a profile of anorexia, hematochezia and oliguria, with the urine acquiring an orange coloration and a strong smell. On the same day, the animal underwent fluid therapy with lactated Ringer's solution ${ }^{1}$ $(5 \mathrm{~mL} / \mathrm{kg})$ and prescribed a pharmacotherapy based on gastric protectors and antimicrobial agents.

Two days after the first consultation, the animal returned presenting apathy, vocalization, lack of coordination, spasms on the limbs, twitching, adipsia, anuria and inability to defecate. A clinical examination revealed that the mucosae presented normal coloration, low temperatures $\left(<33^{\circ} \mathrm{C}\right)$ and moderate dehydration. The examination also revealed dyspnea (36 mpm) and slight hyperglycemia ( $187 \mathrm{mg} / \mathrm{dL})$, in addition to distension of the abdomen and of the urinary bladder.

The hematological and the serum biochemistry analysis presented results compatible with normocytic, normochromic regenerative anemia, evidenced by red blood cell count of $4.4710^{6} / \mu \mathrm{L}$, hemoglobin level of $6.5 \mathrm{~g} / \mathrm{dL}$, hematocrit level of $20(\mathrm{vg}) \%$, and thrombocytopenia (platelets $40.400 / \mu \mathrm{L})$, in addition to leukocytosis (21.7 103/ $\mu \mathrm{L})$, neutrophilia $(18.7 \mu \mathrm{L})$ and slight uremia 65.5 $\mathrm{mg} / \mathrm{dL}$ (42.8-64.2 $\mathrm{mg} / \mathrm{dL})$. Due to the severity of the neurologic signs and lack of response to the clinical treatment, the choice was made to euthanize the animal and conduct a necropsy. The necropsy reveled diffuse jaundice in the mucosae, serosae and subcutaneous layer, with kidney injuries observed through the pale coloration of the tissue, irregular surface with multiple off-white small nodules distributed in a marked and diffuse way. The same injury pattern was observed markedly in the lungs and discretely in the spleen and liver.

The material collected was fixed in a $10 \%$ formalin solution. A sample from each kidney was processed and embedded in paraffin, sectioned in $4 \mu \mathrm{m}$ pieces and stained with Hematoxylin \& Eosin (H\&E). The remaining samples were submitted to histochemical assays with the Alcian Blue and Masson's Trichrome stains, in addition to an immunohistochemical expression. For this, antigen retrieval was conducted with a citrate buffer solution (Citrate $\mathrm{pH} 6.110 \mathrm{x})^{2}$ in a pressure chamber (Pascal, modelo S2800) ${ }^{3}$ and peroxidase blocking with a commercially-available solution (Protein Block, X0909) ${ }^{3}$. Afterwards, the slides were incubated with the primary antibodies monoclonal mouse anti-vimentin (Clone V9, sc-6260) ${ }^{4}$, monoclonal mouse anti-cytokeratin, pan (Clone AE1/AE3, sc-81714) ${ }^{4}$ and monoclonal mouse antip63 (Clone 4A4, sc- 8431) ${ }^{4}$. The polymer system was used as secondary antibody (Envision) ${ }^{3}$ and the slides were stained with Harris' hematoxylin. Normal skin samples from a cat were used as a positive control and the substitution of the primary antibody for the buffer solution was used as a negative control. The samples were evaluated for the presence or absence of markings.

A microscopic analysis revealed multiple focuses of pyogranulomatous injuries in the kidneys, lungs, spleen, uvea and leptomeninges, corroborating the diagnosis of feline infectious peritonitis (FIP). However, a benign mesenchymal neoplasm was also noted in the renal interstitium (Figure 1A), characterized by extensive, well-outlined areas with proliferation of elongated and star-shaped cells with 


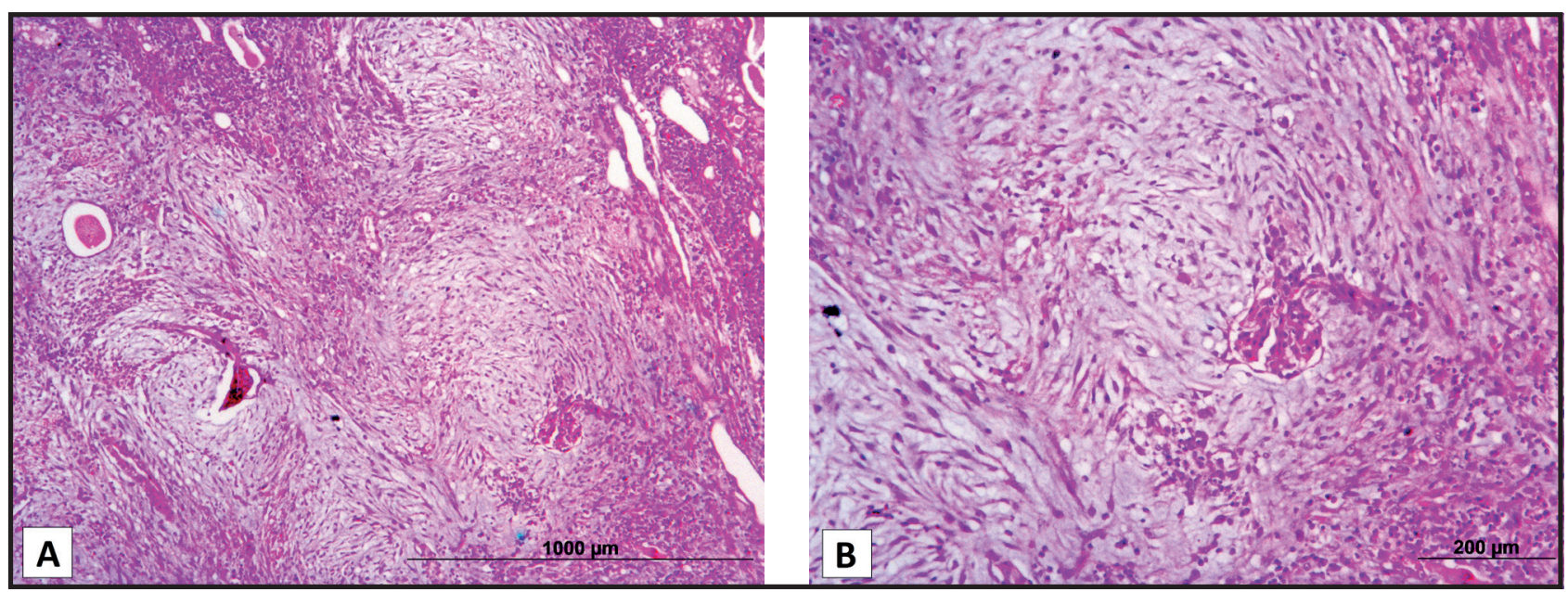

Figure 1. A- Renal mesenchymal neoplasm consisting of elongated, star-shaped cells in the middle of myxoid stroma [H\&E; 50x]. B- 'Hijacked' glomerulus in the middle of a benign myxomatous neoplastic proliferation [H\&E; 200x].

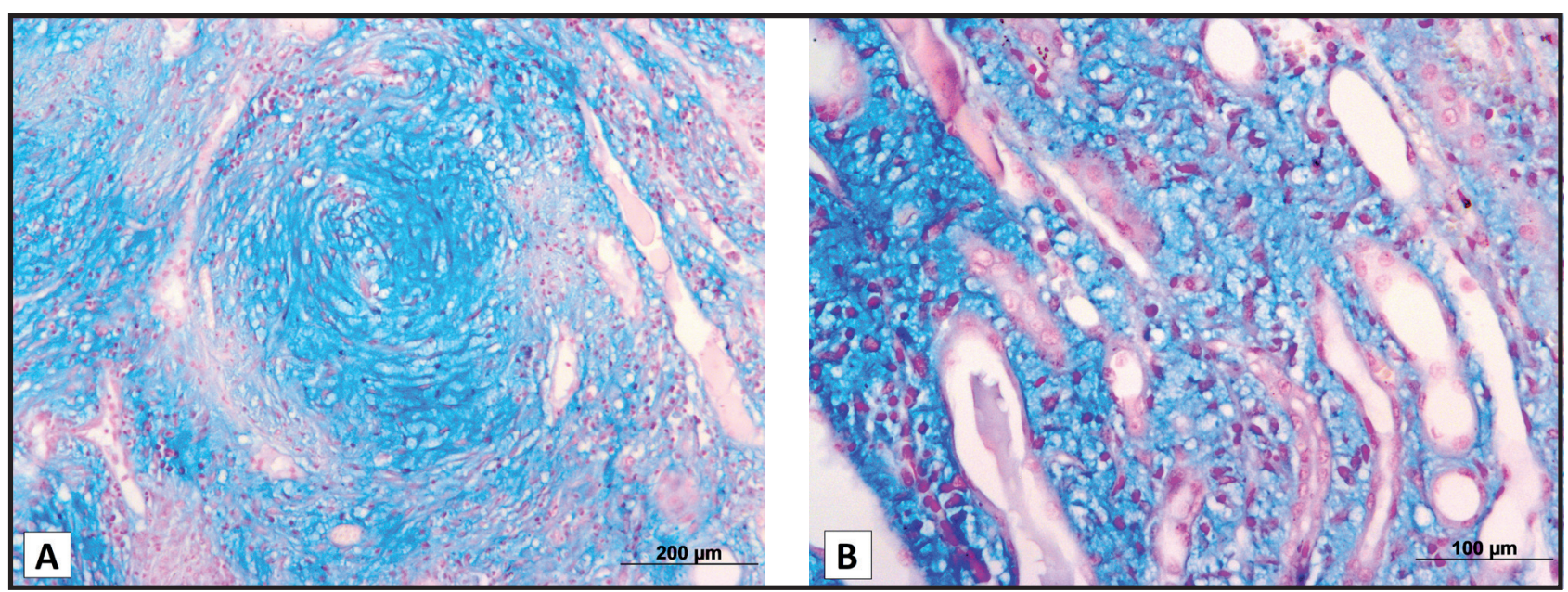

Figure 2. A- Fusiform star-shaped cells arranged in 'nests' and dispersed in abundant myxoid matrix [Alcian Blue; 100x]. B- Cells and myxoid matrix as seen in the interstitium of the renal tubules [Alcian Blue; 100x].

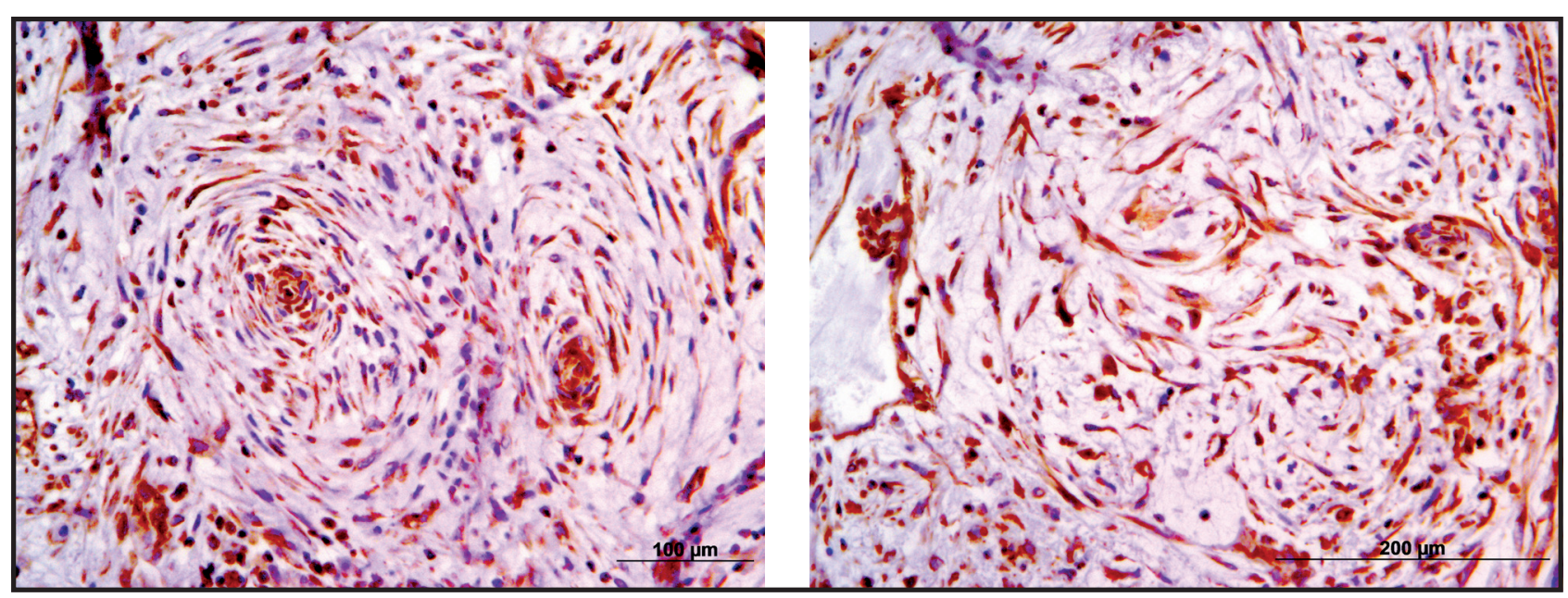

Figure 3. The neoplastic cells presented immunoreactivity and strong positive marking for vimentin.

cellular pleomorphism and absent mitoses, associated with myxoid material confirmed with the Alcian Blue stain (Figure 2). The neoplastic cells occasionally surrounded normal renal tissue such as glomeruli or tubules (Figures 1B \& 2B) and presented a scarce eosinophilic cytoplasm, oval nucleus, loose chromatin and conspicuous nucleolus, which were stained red in Masson's Trichrome stain. 
The immunohistochemical assay revealed that the neoplastic cells were positive for Vimentin (Figure 3 ) and negative for pan-cytokeratin and p63.

\section{DISCUSSION}

Myxomas were originally described in 1863 by Virchow [11], being named after and compared with structures similar to the mucous tissue in the umbilical cord. In 1948, Stout [10] determined that the myxoma was a tumor of fusiform or star-shaped cells presenting a myxoid stroma with mucopolysaccharides which, in turn, intersperse delicate reticular fibers in several directions.

The causa mortis of the animal described in this case report is not related with the direct action of the tumor. We believe that the infection caused by FIP and the presence of a granuloma in the kidney induced a chronic injury resulting in a profile of uremia and severe neurologic alterations. This is in line with the literature, which describes the myxoma as a benign neoplasm with slow growth, absence of metastases and accidental diagnosis [7]. The morphologic analysis allowed the differentiation between a benign and a malignant tumor, particular regarding criteria of cellular pleomorphism and mitotic index. According to Souza et al. [9], the mitotic index of benign neoplasms is rare or non-existent, allowing the confirmation of the initial diagnosis.

The morphologic findings, together with the histochemical and immunohistochemical techniques, allowed a definitive diagnosis. The Alcian Blue stain marked an extracellular myxoid component, which was highlighted in shades of blue interspersed with neoplastic cells, contributing to the diagnosis of myxoma. However, to differentiate between neoplasms with a myxoid component in benign tumors, Masson's Tri- chrome technique stained the neoplastic cells in red, excluding the possibility of fibroblastic origin in this case.

The immunophenotypic characteristics of the cells highlighted the mesenchymal nature of the neoplastic cells through immunoreactivity in the presence of the antibody Vimentin, being negative for epithelial and myoepithelial origin, based in the negative marking for pan-cytokeratin and P-63 respectively. The histopathological assay, together with the findings evidenced by these antigen expression techniques, resulted in a diagnosis of renal myxoma for the feline.

Kidney tumors are rare in veterinary medicine, but have an incidence rate four to five times greater in cats than in dogs. Considering neoplasms of primary origin, the renal carcinoma and the nephroblastoma are the most common, representing only $1 \%$ of the cases described [7], but renal lymphomas are related to secondary neoplasms more often in the species [4]. Previous reports of myxomas in veterinary medicine described tumors located in joints [2], cardiac valves $[3,1]$ and ureter [6], but reports of myxomas afflicting the kidneys are more commons in human medicine. It is necessary to differentiate a myxoma from other neoplasms that could potentially be associated with the secondary myxoid matrix. This is the first reported case of renal myxoma afflicting a young feline with feline infectious peritonitis (FIP) in the veterinary literature.

\section{MANUFACTURERS}

\footnotetext{
1JP - Indústria Farmacêutica S.A. Ribeirão Preto, SP, Brazil. ${ }^{2}$ Agilent Technologies. Santa Clara, CA, USA.

${ }^{3}$ Dako North America Inc. Carpinteria, CA, USA.

${ }^{4}$ Santa Cruz Biotechnology. Dallas, TX, USA.
}

Declaration of interest. The authors report no conflicts of interest. The authors alone are responsible for the content and writing of the paper.

\section{REFERENCES}

1 Akkoc A., Ozyigit M.O. \& Cangul I.T. 2007. Valvular Cardiac Myxoma in a Dog. Journal of Veterinary Medicine. A, Physiology, Pathology, Clinical Medicine. 54(7): 356-358.

2 Craig L.E., Krimer P.M. \& Cooley A.J. 2010. Canine Synovial Myxoma: 39 cases. Veterinary Pathology. 47(5): 931-936.

3 Machida N., Hoshi K., Kobayashi M., Katsuda S. \& Yamane Y. 2003. Cardiac Myxoma of the tricuspid valve in a dog. Journal of Comparative Pathology. 129(4): 320-324.

4 Meuten D.J. \& Meuten T.L.K. 2017. Tumors of Urinary System. In: Meuten D.J. (Ed). Tumors in Domestic Animals. 5th edn. Ames: Wiley Blackwell, pp.632-688.

5 Pinede L., Duhaut P. \& Loire R. 2001. Clinical presentation of left atrial cardiac myxoma. A series of 112 consecutive cases. Medicine. 80(3): 159-172. 
6 Rubin J.A. 2018. Ureteral obstruction secondary to an extraluminal myxoma in a cat. Companion Animal. 23(2): 9093.

7 Serakides R. \& Silva J.F. 2016. Sistema urinário. In: Santos R.L. \& Alessi A.C. (Eds). Patologia Veterinária. $2 . e d$. São Paulo: Editora Roca, pp.167-310.

8 Simon E.N.M., Merkx M.A.W., Vuhahula E., Ngassapa D. \& Stoelinga P.J.W. 2004. Odontogenic myxoma: a clinicopathological study of 33 cases. International Journal of Oral and Maxillofacial Surgery. 33(4): $333-337$.

9 Souza C.H.C., Carneiro K.S., Leite K.R.M., Almeida Junior A. \& Costa A.S. 2015. Renal myxoma: a case report. Jornal Brasileiro de Patologia e Medicina Laboratorial. 51(2): 113-116.

10 Stout A.P. 1948. Myxoma, the tumor of primitive mesenchyme. Annals of Surgery. 127(4): 706-719.

11 Virchow R. 1863. Die Krankhaften Geschwulste. v.1. Berlin: Hischwad, pp.369-434. 